\title{
Students and Educators Attitudes towards the use of M- Learning: Gender and Smartphone ownership Differences
}

\author{
https://doi.org/10.3991/ijim.v13i01.9374 \\ Mostafa Al-Emran( $(\varpi)$ \\ Universiti Malaysia Pahang, Gambang, Malaysia \\ malemran@buc.edu.om \\ Yahya Ashour Alkhoudary \\ Al Buraimi University College, Al Buraimi, Oman \\ Vitaliy Mezhuyev \\ Universiti Malaysia Pahang, Gambang, Malaysia \\ Mohammed Al-Emran \\ Al Buraimi University College, Al Buraimi, Oman
}

\begin{abstract}
Mobile learning (M-learning) is relatively becoming a hot topic that attracted the interest of many scholars. Although M-learning is spreading rapidly across many countries in the world, studying the students and educators' attitudes towards its usage is still in short supply. This study is considered one of the few that attempts to examine the students and educators' attitudes towards the use of M-learning by focusing on gender and smartphone ownership differences. The data were collected through a questionnaire survey from eight different universities in Dubai, United Arab of Emirates. 141 students and 31 academics participated in the study. The results indicated that the male students and academics were more likely to use the M-learning systems than the females. Moreover, the students and academics who own smartphones were more likely to use the M-learning systems than those who do not so.
\end{abstract}

Keywords-M-learning, Attitudes, Gender, Smartphone ownership.

\section{Introduction}

Due to the rapid growth of mobile computing devices (e.g. smartphone, tablets) in the last decade, mobile devices have been successfully incorporated into several streams; learning is one of them. Mobile learning (M-learning) refers to "the learning across multiple contexts, through social and content interactions, using personal electronic devices" [1]. M-learning has been viewed as the learning that provides the students with the constant connectivity to access their course material on anytime anywhere settings [2], and enhances their experiences via distance learning [3]. M- 
learning has brought numerous advantages for the higher education segment. As such, M-learning enhances the interaction and communication among the students and their educators [4]. In addition, M-learning empowers learners with disabilities to perform effectively and efficiently in their classrooms [5].

It is argued that the importance of M-learning has become a reality in today's education [6]. This trend has affected various sectors other than the educational sector such as the communication and medicine sectors [7]. In that, the way the learners interact and communicate among each other has evolved rapidly. In line with this issue, a plethora of research articles has been conducted regarding the usage of mobile computing devices in education [8]. In general, M-learning has proved its effectiveness to be a learning medium that enhances the students' experiences and learning across a wide range of universities [9].

Different research studies were carried out to examine different research trends concerning M-learning, some of them tries to measure the students and instructors' attitudes [3], [10], [11], some tries to measure the effectiveness of M-learning on students [12], and some have determined the benefits and drawbacks of the technology [2]. The primary aim of the study is to measure both the students and educators' attitudes towards the use of M-learning in eight different universities in the United Arab of Emirates (UAE). The understanding of these attitudes will provide an insight into the incorporation of these technologies into the learning process.

\section{$2 \quad$ Literature Review}

M-learning is fast becoming a dominant field of research in the context of educational technology [13]. It is claimed that studying the attitudes towards M-learning is used to measure the extent to which the learners and educators have the inspiration to use the technology [11]. Several research studies were carried out to measure the students' attitudes towards the use of M-learning.

A study carried out by [12] attempted to measure the students and academics' attitudes towards the use of M-learning at King Saud University (KSA). The results indicated that $80 \%$ of both students and academics were aware of M-learning and they exerted positive attitudes towards its usage. Another study carried out by [14] attempted to study the adults educators' attitudes towards the use of M-learning in eight European countries. The results pointed out that those educators were aware of the use of M-learning and they were highly motivated towards its usage. Another study conducted by [10] indicated that students' attitudes towards M-learning adoption at "Midwestern University" (USA) were more positive than those in the "Higher Colleges of Technology" (UAE). It also showed that females were more positive than males towards M-learning. A study carried out by [15] tried to measure the students' attitudes towards the usage of M-learning in two neighboring countries, namely Oman and UAE. The results indicated that students in the UAE were more positive towards the use of M-learning than those in Oman.

Recently, it is pointed out by a study conducted by [16] in three different countries (Turkey, USA, and China), that learners are fully aware of M-learning, and most of 
them indicated that they were already involved in many mobile-based learning activities. In addition, it is claimed by [7] that $57 \%$ of the medical students are using their mobile devices for educational purposes and they have strong willingness to recommend this educational technology to other students. Besides, another study carried out by [17], indicated through a quasi-experimental design in Taiwan, that M-learning has a positive effect on the students' learning motivation and achievements. In addition, a study carried out by [18] attempted to examine the academics' acceptance of Mlearning in Kuwait. The results pointed out that the academics have moderately positive attitudes towards the acceptance of M-learning regardless of age and gender differences. Also, a study conducted by [19], revealed that iPad-based M-learning is an effective gadget for problem-based learning in the UK, and it could create a new pedagogical model.

According to the extant literature, very limited number of M-learning studies were carried out in the Gulf region, in general, and the United Arab of Emirates (UAE) in particular. In addition, there are many issues that have not yet examined and require further investigation. In that, differences in gender and smartphone ownership are important factors that need to be examined from the perspective of M-learning. Moreover, a few number of studies has focused on examining the educators' attitudes towards the use of M-learning. Based on the previous assumptions, the main objective of this study is to examine the students and educators' attitudes towards the use of Mlearning in eight different universities in the UAE by focusing on the gender and smartphone ownership differences.

In order to achieve this aim, this study posits the following research questions:

RQ1. Is there any significant difference among the students' attitudes towards the use of M-learning with regard to gender?

RQ2. Is there any significant difference among the students' attitudes towards the use of M-learning with regard to smartphone ownership?

RQ3. Is there any significant difference among the academics' attitudes towards the use of M-learning with regard to gender?

RQ4. Is there any significant difference among the academics' attitudes towards the use of M-learning with regard to smartphone ownership?

\section{Research Methodology}

\subsection{Sample and study instrument}

The data were collected from eight different universities in Dubai, United Arab of Emirates. These universities include The British University in Dubai, SZABIST Dubai, Murdoch University Dubai, Amity University Dubai, BITS Pilani, Heriot-Watt University Dubai, Université Saint Joseph Law School - Dubai, and The American University in the Emirates. Two questionnaire surveys were used for the purpose of data collection. The first one was dedicated to collect data from the students, whereas, the second one was used to collect data from the academics. 141 students and 31 academics participated in the study. The participated students were randomly selected 
from different academic majors and different degrees. Similarly, the participated academics were also randomly selected from different faculties and different academic ranks.

\subsection{Surveys structures}

Each of the two questionnaire surveys consists of two sections. The first section related to demographic information such as gender, smartphone ownership, age, faculty, and university name. The second section consists of 5 items which were related to the students and educators' attitudes towards the use of M-learning. A five-point Likertscale with "strongly disagree (1), disagree (2), neutral (3), agree (4), and strongly agree (5)" was used.

\subsection{Measurement analysis}

In order to measure the internal consistency reliability of the items, the Cronbach's Alpha has been calculated. As suggested by [20], the Cronbach's Alpha values should be greater than 0.7 in order to be accepted. The Cronbach's Alpha values for the students' items were 0.794 and for the academics' items were 0.901 , which were both greater than 0.7 . In that, the internal consistency reliability is confirmed.

\section{$4 \quad$ Results}

RQ1. Is there any significant difference among the students' attitudes towards the use of M-learning with regard to gender?

In order to examine if there any significant difference among the students' attitudes toward the use of M-learning with regard to their genders, an independent samples $t$ test was calculated to determine the statistical difference. Based on Table 1, the results indicated that there is a statistically significant difference among the students' attitudes in terms of their gender $(p=0.041 ., p<=0.05)$; the differences were in favor of male students.

Table 1. Differences among students' attitudes with regard to gender.

\begin{tabular}{|l|c|c|c|c|c|c|}
\hline \multicolumn{1}{|c|}{ Gender } & N & Mean & Std. Dev. & t-value & Df & Sig. \\
\cline { 1 - 4 } Male & 62 & 4.0548 & 0.62743 & 2.060 & 139 & 0.041 \\
\hline Female & 79 & 3.7873 & 0.85775 & & & \\
\hline
\end{tabular}

RQ2. Is there any significant difference among the students' attitudes towards the use of M-learning with regard to smartphone ownership?

In order to investigate if there any significant difference among the students' attitudes toward the use of M-learning in terms of smartphone ownership, an independent samples $t$-test was calculated to determine the statistical difference. According to Table 2 , the results pointed out that there is a statistically significant difference among the students' attitudes in terms of their smartphone ownership ( $p=0.034 ., p<=0.05)$; the differences were in favor of those who own smartphones. 
Table 2. Differences among students' attitudes with regard to smartphone ownership.

\begin{tabular}{|l|c|c|c|c|c|c|}
\hline \multicolumn{1}{|c|}{ Smartphone ownership } & N & Mean & Std. Dev. & t-value & Df & Sig. \\
\hline Yes & 137 & 3.9285 & 0.75410 & 2.137 & 139 & 0.034 \\
\cline { 1 - 5 } No & 4 & 3.1000 & 1.13725 & & & \\
\hline
\end{tabular}

RQ3. Is there any significant difference among the academics' attitudes towards the use of M-learning with regard to gender?

In order to examine if there any significant difference among the academics' attitudes toward the use of M-learning with regard to their genders, an independent samples $t$-test was calculated to determine the statistical difference. Based on Table 3, the results indicated that there is a statistically significant difference among the academics' attitudes in terms of their gender ( $p=0.047 ., p<=0.05)$; the differences were in favor of male academics.

Table 3. Differences among academics' attitudes with regard to gender.

\begin{tabular}{|l|c|c|c|c|c|c|}
\hline \multicolumn{1}{|c|}{ Gender } & $\mathbf{N}$ & Mean & Std. Dev. & t-value & Df & Sig. \\
\hline Male & 23 & 4.0174 & 0.89831 & 2.070 & 29 & 0.047 \\
\hline Female & 8 & 3.2750 & 0.79237 & & & \\
\hline
\end{tabular}

RQ4. Is there any significant difference among the academics' attitudes towards the use of M-learning with regard to smartphone ownership?

In order to investigate if there any significant difference among the academics' attitudes toward the use of M-learning in terms of smartphone ownership, an independent samples $t$-test was computed to determine the statistical difference. According to Table 4, the results pointed out that there is a statistically significant difference among the academics' attitudes in terms of their smartphone ownership ( $p=0.038 ., p<=$ $0.05)$; the differences were in favor of those who own smartphones.

Table 4. Differences among academics' attitudes with regard to smartphone ownership.

\begin{tabular}{|l|c|c|c|c|c|c|}
\hline \multicolumn{1}{|c|}{ Smartphone ownership } & N & Mean & Std. Dev. & t-value & Df & Sig. \\
\cline { 1 - 7 } Yes & 25 & 3.9920 & 0.78842 & 2.176 & 29 & 0.038 \\
\cline { 1 - 6 } No & 6 & 3.1333 & 1.17757 & & & \\
\hline
\end{tabular}

\section{Discussion}

In order to measure the students and academics' attitudes towards the use of Mlearning in the UAE, four research questions were formulated. In terms of the first research question which concerns about studying the students' attitudes towards the use of M-learning with regard to gender, the results indicated that male students were more positive than females towards the use of M-learning. This result indicates that male students are more interested to use the M-learning systems than the females. This result is in agreement with the results revealed by [21]. On the other side, these results contradict with other studies like [22], [23], in which these studies did not reveal any significant difference between the students' genders. With regard to the second research question which concerns about measuring the students' attitudes 
towards the use of M-learning with regard to smartphone ownership, the results revealed that those who own smartphones were more positive than those who don't towards the use of M-learning. This result indicates that students who own smartphones are more likely to use the M-learning systems than those who don't so. Additionally, smartphone owners have already acquired the sufficient experience in using mobile devices, and therefore, this could enhance their behavioral intention to use the M-learning systems.

With respect to the third research question which concerns about measuring the academics' attitudes towards the use of M-learning with regard to gender, the findings pointed out that male academics were more positive than females towards the use of M-learning. This result suggests that the male academics are more interested to use the M-learning systems than the females. However, this result contradicts with the results indicated by [15], in which no significant difference was found among the academics' attitudes with regard to their genders. Regarding the fourth research question which concerns about examining the academics' attitudes towards the use of Mlearning with regard to smartphone ownership, the findings indicated that those who own smartphones were more positive than those who don't towards the use of Mlearning. This result indicates that academics who own smartphones are more likely to use the M-learning systems than those who don't so. This can also refer to the experience that the academics acquired while using mobile devices which is not the case with those who don't.

\section{Conclusion and Future Work}

During the last decade, educational technologies have become a trendy domain that attracts many scholars [24], [25]. M-learning as one of such technologies enables the students to access their learning materials in anytime anywhere settings. Studying the students and educators' attitudes is considered an important issue that could determine the strengths and weaknesses of a particular technology. The attitudes towards Mlearning is an essential issue that still needs further exploration. According to the extant literature, it has been noticed that research has overlooked studying the students and educators' attitudes towards the use of M-learning in the UAE. Therefore, this study is regarded as one of the few that attempts to study the students and educators' attitudes towards the use of M-learning with more focus on gender and smartphone ownership differences. 141 students and 31 academics participated in the study. According to the results, it has been noticed that the male students and academics were more likely to use the M-learning systems than the females. In addition, students and academics who own smartphones were more likely to use the M-learning systems than those who do not so.

Although this study yielded significant results regarding the students and academics' attitudes towards the use of M-learning in general, and the UAE context in particular, it also has some limitations that need to be examined in future research. This study has focused on two factors only (i.e., gender and smartphone ownership) in determining the students and academics' attitudes toward the use of M-learning. Fu- 
ture research should consider this limitation and attempt to add other factors such as age and major in terms of the students, and age, specialization, and academic rank in terms of the academics. Moreover, the sample size is quite small. Thus, further research could replicate this study by collecting data from a larger sample. Furthermore, this study has relied on questionnaire surveys for data collection. Hence, further research is suggested to collect data using other data collection techniques such as interviews and focus groups.

\section{$7 \quad$ References}

[1] H. Crompton, "A historical overview of mobile learning: Toward learner-centered education," in Handbook of mobile learning, 2013.

[2] J. Gikas and M. M. Grant, "Mobile computing devices in higher education: Student perspectives on learning with cellphones, smartphones \& social media," Internet High. Educ., vol. 19, pp. 18-26, 2013. https://doi.org/10.1016/j.iheduc.2013.06.002

[3] F. N. Al-Fahad, "Students' Attitudes and Perceptions Towards the Effectiveness of Mobile

[4] Learning in King Saud University, Saudi Arabia," Turkish Online J. Educ. Technol. -, vol. 8, no.10, pp. 1303-6521, 2009.

[5] M. Al-Emran, V. Mezhuyev, and A. Kamaludin, "Students' Perceptions towards the Integration of Knowledge Management Processes in M-learning Systems: A Preliminary Study," Int. J. Eng. Educ., vol. 34, no. 2, pp. 371-380, 2018.

[6] C. Beaton, "Work in progress: Tablet PC's as a leveling device!," in Proceedings Frontiers in Education Conference, FIE, 2006.

[7] M. Al-Emran, V. Mezhuyev, A. Kamaludin, and M. AlSinani, "Development of Mlearning Application based on Knowledge Management Processes," in 2018 7th International conference on Software and Computer Applications (ICSCA 2018), 2018, pp. 248-253. https://doi.org/10.1109/FIE.2006.322475

[8] L. Briz-Ponce, A. Pereira, L. Carvalho, J. A. Juanes-Méndez, and F. J. García-Peñalvo, "Learning with mobile technologies - Students' behavior," Comput. Human Behav., vol. 72, pp. 612-620, 2017. https://doi.org/10.1016/j.chb.2016.05.027

[9] L. B. Ponce, J. A. J. Mendez, and F. J. G. Penalvo, "A systematic review of using mobile devices in medical education," in 2014 International Symposium on Computers in Education, SIIE 2014,2014. https://doi.org/10.1109/SIIE.2014.7017731

[10] G. ALFarsi and M. ALSinani, "Developing a Mobile Notification System for Al Buraimi

[11] University College Students," Int. J. Inf. Technol. Lang. Stud., vol. 1, no. 1, pp. 10-16, 2017

[12] F. Khaddage and G. Knezek, "iLearn via mobile technology: a comparison of mobile learning attitudes among university students in two nations," in Advanced Learning Technologies (ICALT), 2013 IEEE 13th International Conference, 2013, pp. 256-258.

[13] M. Al-Emran and K. Shaalan, "Academics' Awareness Towards Mobile Learning in Oman,” Int. J. Comput. Digit. Syst., vol. 6, no. 1, pp. 45-50, 2017. https://doi.org/10.127 85/IJCDS/060105

[14] H. R. Abachi and G. Muhammad, "The impact of m-learning technology on students and educators," Comput. Human Behav., vol. 30, pp. 491-496, 2014. https://doi.org/10.1016 j.chb.2013.06.018

[15] W.-H. Wu, Y.-C. J. Wu, C.-Y. Chen, H.-Y. Kao, C.-H. Lin, and S.-H. Huang, "Review of trends from mobile learning studies: A meta-analysis," Comput. Educ., vol. 59, no. 2, pp. 817-827, 2012. https://doi.org/10.1016/j.compedu.2012.03.016 
[16] M. Demirbilek, "Investigating Attitudes of Adult Educators towards Educational Mobile Media and Games in Eight European Countries," J. Inf. Technol. Educ., vol. 9, pp. 235247, 2010. https://doi.org/10.28945/1327

[17] M. Al-Emran and K. Shaalan, "Attitudes towards the use of mobile learning: A case study from the gulf region," Int. J. Interact. Mob. Technol., vol. 9, no. 3, pp. 75-78, 2015. https://doi.org/10.3991/ijim.v9i3.4596

[18] S. Hao, M. Cui, V. P. Dennen, Y. K. Türel, and L. Mei, "Analysis of mobile learning as an innovation in higher education: a comparative study of three countries," Int. J. Mob. Learn.Organ., vol. 11, no. 4, pp. 314-339, 2017. https://doi.org/10.1504 /IJMLO.2017.087080

[19] C.-H. Tsai, C.-H. Cheng, D.-Y. Yeh, and S.-Y. Lin, "Can learning motivation predict learning achievement? A case study of a mobile game-based English learning approach," Educ. Inf. Technol., vol. 22, no. 5, pp. 2159-2173, 2017. https://doi.org/10.1007/s10639$\underline{016-9542-5}$

[20] A. Al-Hunaiyyan, R. Alhajri, and S. Al-Sharhan, "Instructors Age and Gender Differences in the Acceptance of Mobile Learning," Int. J. Interact. Mob. Technol., 2017.

[21] Y. Li and L. Wang, "Using iPad-based mobile learning to teach creative engineering within a problem-based learning pedagogy," Educ. Inf. Technol., vol. 23, no. 1, pp. 555568, 2018. https://doi.org/10.1007/s10639-017-9617-y

[22] J. F. Hair, W. C. Black, B. J. Babin, and R. E. Anderson, Multivariate Data Analysis. New Jersey, 2010.

[23] M. Al-Emran and S. A. Salloum, "Students' Attitudes Towards the Use of Mobile Technologies in e-Evaluation," Int. J. Interact. Mob. Technol., vol. 11, no. 5, pp. 195-202, 2017. https://doi.org/10.3991/ijim.v11i5.6879

[24] Y. S. Wang, M. C. Wu, and H. Y. Wang, "Investigating the determinants and age and gender differences in the acceptance of mobile learning," Br. J. Educ. Technol., vol. 40, no. 1, pp. 92-118, 2009. https://doi.org/10.1111/j.1467-8535.2007.00809.x

[25] H. Uzunboylu, N. Cavus, and E. Ercag, "Using mobile learning to increase environmental awareness," Comput. Educ., vol. 52, no. 2, pp. 381-389, 2009. https://doi.org/10.1016/ j.compedu.2008.09.008

[26] R. A. S. Al-Maroof and M. Al-Emran, "Students Acceptance of Google Classroom: An Exploratory Study using PLS-SEM Approach,” Int. J. Emerg. Technol. Learn., vol. 13, no. 6, pp.112-123, 2018. https://doi.org/10.3991/ijet.v13i06.8275

[27] S. A. Salloum, M. Al-Emran, K. Shaalan, and A. Tarhini, "Factors affecting the E-learning acceptance: A case study from UAE," Educ. Inf. Technol., 2018.

\section{Authors}

Mostafa Al-Emran is a Ph.D. candidate in computer science at Universiti Malaysia Pahang. He has published over 35 research papers in highly reputed journals such as Computers in Human Behavior, Computers \& Education, International Journal of Information Management, and IEEE Access, among many others. He is a certified recognized reviewer by several leading journals in Elsevier. His current research interests include technology adoption, knowledge management, and text mining.

Yahya Ashour Alkhoudary is an assistant professor of Linguistics. He has a $\mathrm{PhD}$ in Applied Linguistics, University of Malaya; an MA in English, IUP, USA. His areas of interest include lexical semantics, acquisition of lexis, the use of psychometric tools in investigating mental lexicon content and organization. Moreover, he was 
granted Sheikh Hamadan Bin Rashid's Award for the distinguished researcher in the UAE.

Vitaliy Mezhuyev received his $\mathrm{PhD}$ in Educational Technology from Kiev National Pedagogical University, Ukraine, in 2002, and a ScD in Information Technology from Odessa National Technical University, Ukraine, in 2012. Currently, he is a Professor at the Faculty of Computer Systems \& Software Engineering in Universiti Malaysia Pahang, and the Head of Software Engineering Research Group. During his career, Mezhuyev participated in multiple international scientific and industrial projects, devoted to the formal modelling, design, and development of advanced software systems.

Mohammed Al-Emran received the bachelor's degree in English language and literature from Al Buraimi University College. He is mainly interested in conducting research related to educational technology.

Article submitted 10 August 2018. Resubmitted 20 October and 02 November 2018. Final acceptance 14 November 2018 . Final version published as submitted by the authors. 